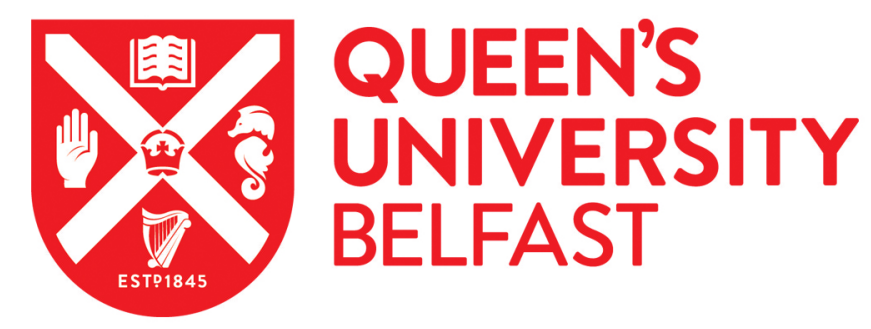

\title{
Is Longer-Distance Migration Slowing? An Analysis of the Annual Record for England and Wales since the 1970s
}

Champion, T., \& Shuttleworth, I. (2016). Is Longer-Distance Migration Slowing? An Analysis of the Annual Record for England and Wales since the 1970s. Population, Space and Place, 23(3), [e2024].

https://doi.org/10.1002/psp.2024

Published in:

Population, Space and Place

Document Version:

Peer reviewed version

Queen's University Belfast - Research Portal:

Link to publication record in Queen's University Belfast Research Portal

Publisher rights

Copyright @ 2016 John Wiley \& Sons, Ltd.

This is the peer reviewed version of this following article that has been published in final form at DOI:10.1002/psp.2024. This article may be used for non-commercial purposes in accordance with Wiley Terms and Conditions for Self-Archiving.

\section{General rights}

Copyright for the publications made accessible via the Queen's University Belfast Research Portal is retained by the author(s) and / or other copyright owners and it is a condition of accessing these publications that users recognise and abide by the legal requirements associated with these rights.

Take down policy

The Research Portal is Queen's institutional repository that provides access to Queen's research output. Every effort has been made to ensure that content in the Research Portal does not infringe any person's rights, or applicable UK laws. If you discover content in the Research Portal that you believe breaches copyright or violates any law, please contact openaccess@qub.ac.uk. 


\title{
Is Longer-Distance Migration Slowing? An Analysis of the Annual Record for England and Wales since the 1970s
}

\author{
Tony Champion, Centre for Urban and Regional Development Studies, \\ Newcastle University, Newcastle upon Tyne, UK, and Ian Shuttleworth, \\ School of Geography, Archaeology and Palaeoecology, Queen's \\ University Belfast, Belfast, UK
}

\begin{abstract}
This paper is prompted by the widespread acceptance that the rates of inter-county and inter-state migration have been falling in the USA and sets itself the task of examining whether this decline in migration intensities is also the case in the UK. It uses annual inter-area migration matrices available for England and Wales since the 1970s by broad age group. The main methodological challenge, arising from changes in the geography of health areas for which the inter-area flows are given, is addressed by adopting the lowest common denominator of 80 areas. Care is also taken to allow for the effect of economic cycles in producing short-term fluctuations on migration rates and to isolate the effect of a sharp rise in rates for 16-24 year olds in the 1990s, which is presumed to be related to the expansion of higher education. The findings suggest that, unlike for the USA, there has not been a substantial decline in the intensity of internal migration between the first two decades of the study period and the second two. If there has been any major decline in the intensity of address changing in England and Wales, it can only be for the within-area moves that this time series does not cover. This latter possibility is examined in a companion paper using a very different data set (Champion and Shuttleworth, 2016).
\end{abstract}

Keywords: internal migration; migration intensity; between-area moves; long-term trend; England and Wales

\section{INTRODUCTION}

It appears to be conventional wisdom that the world is becoming increasingly mobile and that we are living in 'the age of migration', yet there is some evidence that the propensity to move home has begun to decline (see Cooke, 2013, for a review). So far this phenomenon has been most extensively documented for the USA where the decline in internal migration rates dates back to at least the 1980s, but research on a new repository of internal migration records from around the globe suggests that this is not an isolated case (Bell and Charles-Edwards, 2013; Bell et al., 2015a). As yet, however, that project does not provide a time-series analysis of the situation in the UK. There the most recent study (Lomax et al., 2014) reveals a marked decline in the internal migration rate, but covers only the decade 2001-2011 and associates this change primarily with the latest in a series of recessions that have caused only temporary dips in migration intensity. 
The aim of this paper is to track internal migration for England and Wales over a considerably longer period than the latest decade in order to discover whether its intensity has been declining as in the USA. The analysis draws on the UK's National Health Service Central Register (NHSCR), which has continuously monitored migration there since the 1970s, thereby spanning several business cycles and facilitating the process of detecting any secular trends in rates. Though the NHSCR's coverage of address changing is limited to between-area moves, this is consistent with the main thrust of research on the US experience which is on inter-county migration. Also, moves can be classified according to whether or not they cross a higher-level regional boundary, paralleling the US distinction between within- and between-state migration. A companion paper (Champion and Shuttleworth, 2016) reports the findings obtained from interrogating a very different data set that, while based on observations taken just once every 10 years, includes all distances of move and contains more information on people's characteristics.

The paper begins by providing some theoretical and international context including more detail on the US experience. Next, we review previous work on the intensity of internal migration in the UK, demonstrating the value of the NHSCR for this. Even so, this dataset is not straightforward to use, so we then set out the steps taken to derive as consistent a time series as possible before using the latter to ascertain whether a decline in migration rate has occurred long-term. The paper concludes with a preliminary discussion of the findings, anticipating the fuller assessment of their theoretical and policy significance at the end of the companion paper.

\section{THEORETICAL AND INTERNATIONAL PERSPECTIVES}

There seems to be a widely-held belief that we are living in an increasingly mobile society. Witness the frequent mentions of an 'age of migration', of a 'world on the move', of the emergence of a 'hypermobility' that is eroding attachment to place, and of a 'liquid modernity' that is associated with the end of territory and their supersession by 'networks' and 'spaces of flows' (see, for instance, Bauman, 2000; Robbins, 2000; Urry, 2007; Castles and Millar, 2009; Adey, 2010). Ideas linking demographic, economic, environmental, political and social change have a long currency in migration theory, most notably in Lee's (1966) refinement of Ravenstein's nineteenth-century 'laws of migration' and in Zelinsky's (1971) 'hypothesis of the mobility transition'. They have taken on even greater salience with the rise of the New Mobilities Paradigm and the 'mobilities turn' that is said to be transforming the social sciences in an era of globalization (Cresswell, 2006; Hannan et al., 2006; Sheller and Urry, 2006). Additionally, there are more other grounds for the assumption that migration and mobility will increase over the long term, most notably shifts in population composition towards the higher-skilled and more educated 'service class' groups that have traditionally experienced the greatest geographic mobility (Fielding, 2012; Green, 1992; Green and Shuttleworth, 2015).

Yet there are now indications that this assumption of increasing spatial mobility is not true for all types of movement or all geographical contexts. The most comprehensive evidence available is provided by the IMAGE (Internal Migration Around the GlobE) project, which has established an inventory of internal migration data collections for a large number of countries (see Bell et al., 2015a, 2015b). Though this project's work 
so far has been primarily cross sectional, one output (Bell and Charles-Edwards, 2013) includes trend analysis for a sub-sample of countries. As regards the more developed world, their analysis shows that between the 1990 and 2000 rounds of censuses the intensity of five-year address changing declined for Australia, Canada, New Zealand, Switzerland and the USA, rising only in Greece and Portugal. For all three more developed countries for which data was then available from the 2010 census round (Australia, Canada and New Zealand), the five-year intensity had fallen further, though the onset of recession after the worldwide banking crisis of 2007 was no doubt a contributory factor at this time.

It is the USA for which the long-term decline in internal migration rates has been examined most fully and over the longest time span. Cooke (2011) clearly revealed a marked drop in both inter-state and inter-county migration rates, most notably in his chart (p.194) that used Current Population Survey (CPS) data to track annual rates for 1948-2009. The main decline was found to have set in after the early 1980s, at which point the rates were not substantially different from those prevailing in the 1950s, and be especially steep from 1999 onwards. The fact that the latter predated the post-2007 recession by several years prompted an analysis that suggested that 'it is not just the economy' behind this fall but also 'the rise of secular rootedness' (p.193). Even though it has subsequently been recognized that the CPS-based rates for 1999-2005 had been overestimated (Cooke, 2013; Kaplan and Schulhofer-Wuhl, 2012a), this does not undermine Cooke's overall conclusion that migration rates were falling and that this was due to more than a business-cycle effect, not least when taken in conjunction with the fall starting in the 1980s. Moreover, this decline has been confirmed by other datasets and studies including Frey (2009), Kaplan and Schulhofer-Wuhl (2012b, 2012c), Molloy et al. (2011, 2013) and Partridge et al. (2012), as well as being relayed by a number of media reports including Jaffe (2012) and Lowery (2013).

The US literature also provides many potential explanations for declining rates of migration and residential mobility. They would seem to fall into five main groups:

- Population composition has shifted towards the traditionally less migratory groups such as the elderly, owner occupiers and dual-earner households, more than offsetting the effect of the expanding 'service class'

- Places are becoming less differentiated in the availability of lower-paid jobs at the same time as certain types of work are becoming more concentrated in a small number of major cities, both somewhat paradoxically militating against the need to move for job reasons, as too does the filling of more vacancies by migrant labour from other countries

- Changing terms of employment and increasing regulation in labour and housing markets have been raising the barriers to migration, while rising car ownership and more fuel-efficient engines reduce the need to move home when changing jobs

- Home working, weekly commuting and FIFO (Fly In, Fly Out) may also substitute for home moving, while easier access to information on the web may reduce the number of moves that 'fail'

- The trend towards an ever more materialistic society and the rising importance of local social capital make it both more costly and less attractive to move home, this being a key part of Cooke's (2011) suggestion of growing 'secular rootedness'. 
Indeed, there is now such a wide range of hypotheses that it seems strange that there could still have been substantial doubt about this development barely a decade ago when Wolf and Longino (2005) lamented 'the curious persistence of a false belief' in an 'increasingly mobile society'.

Where the literature is still lacking, however, is in discovering the relative importance of these types of explanations. In the meantime, however, most, if not all, of these economic, technical and societal developments are observable across the developed world. Hence this paper's key objective of examining the evidence available from the continuous monitoring of between-area migration for England and Wales since the 1970s. If the same social, demographic, technical, and economic forces have been at work there as in the USA, and in broad outline we argue that they have, it might be expected that there should be broadly similar migration outcomes. Should the England and Wales example differ from that of the USA it queries the idea that deeprooted and long-term historical patterns of change operating across advanced societies necessarily have the same implications for migration rates and perhaps indicates that national context is rather more important than would be implied by developmentalist models such as those of Zelinsky.

\section{STUDYING THE UK}

Migration research has been and continues to be an extremely vibrant element of the social sciences in Britain (see, most notably, Champion and Fielding, 1992; Stillwell et al, 1992a; Fielding, 2012; Smith et al, 2015). Interest in overall rates of migration appears to have been strongest in the earlier decades of migration recording, following the Census's introduction of a question on address one year ago in 1961 and the inception of the continuous monitoring of migration using the NHSCR in 1971. Most of these studies, however, focused on only a relatively short span of years; for instance, Ogilvy (1982) on 1971-79, Devis (1984) on 1971-82, Rosenbaum and Bailey (1991) on 1971-89, Stillwell et al (1992b) on the 1960-89 trend, and ODPM (2002) on 1983-98. As a result, their main findings concerned the way in which the intensity of migration varied with the state of the economy.

More recent migration research has been dominated by qualitative studies of migration behaviour and quantitative studies of the geography of migration flows, the latter most commonly in terms of the role of net migration in population redistribution (see reviews by Fielding, 2012; Smith et al., 2015). An exception is the work of Lomax et al. (2013, 2014), which estimated a consistent time series of data on migration flows between every local authority in the UK and every other one and calculated annual trends in national-level measures of migration intensity (see Lomax et al., 2014, p.30). Their analyses, however, covered only the period 2001-2011 when the principal feature was the impact of the Great Recession in lowering the overall intensity of migration and in slowing the net redistribution of population during the second half of the decade. Also, Champion (2005) included a chart of between-area migration rates for 1975-2004, but it was subsequently discovered that the ONS data used for this was not based on a consistent geography (see below).

A good reason for this dearth of studies on the long-term trend in overall migration intensity is that it is extremely difficult to calculate this in a meaningful and robust 
way. The chief drawback in using Census data for this purpose is the small number of observations, with the sole consistent indicator being the one-year change-of-address question that is asked just once a decade. This is problematic because censuses have occurred at different stages in the business cycle. Additionally, the comparability of census data over time has been undermined by the change in definition of usual residence for students living away from home in term time. Up to the 1991 Census, this was for vacation address, but for 2001 it switched to term-time address, meaning that the migration data from the two latest censuses includes education-related moves.

The NHSCR has several distinct advantages over the Census. It provides a continuous record dating from 1971 for inter-regional migration and from 1975 for intra-regional moves and has always included migration to and from educational establishments insofar as these have been recorded by the health services. Also, apart from for 197583 when only 10 per cent of records were processed for migration monitoring, it has almost 100 per cent coverage of the population, as even those with private-health cover are virtually all registered with the NHS as well. This degree of coverage also marks the NHSCR out from the household surveys and panel studies that have been conducted in the UK over various periods since the 1940s.

The NHSCR also suffers from some deficiencies, but most of them can either be deemed to have minimal impact for present purposes or can be worked around. One is that there will be a time lag between a person moving home and the information about this being recorded in the NHSCR (see Barr and Shuttleworth 2012), but this is allowed for in the dating of the records released. Related to this is that people vary in terms of the speed with which they register their change of address with the NHS, with the likelihood of some people making a second move before the first one has been registered, but ONS assumes that the proportion of address changes thereby missed remains constant over time. More problematic is that, while moves to and from university are included, the degree of coverage of these moves depends on whether or not a student registers with a doctor while at university. While ONS has recently been getting a better handle on this issue by comparing NHS registrations with universities' student lists, there is no way in which the results of that checking can be backdated to the 1970s, so this is an aspect that needs to be born in mind in interpreting the results below.

The biggest challenge of using the NHSCR for time-series research is to ensure that the data relates to a consistent geography. This step is crucial, because unlike the Census its data relates only to migration between health authority areas, excluding within-area moves. This is not a fundamental drawback in itself, in that the US data analysed by Cooke $(2011,2013)$ is also for between-area migration, but it does become an issue if the geography of areas alters over time, which - unlike for the remarkably stable geographies of counties and states in the USA - has occurred rather often in the UK. Spatial reorganisation was something that Lomax et al $(2013,2014)$ had to allow for, even though covering just the one decade 2001-2011, and it was also the cause of the problem with the analysis by Champion (2005), in that the annual data supplied by ONS turns out to have been based on the geography of health areas in place in the respective years. The level of inter-regional migration will be lower for a set of larger (but fewer) areas and higher if the number of areas is increased (e.g. by splitting the previous units and creating more and smaller units). This is a variant of 
the well-known Modifiable Areal Unit Problem (MAUP) that means comparisons through time and between countries must be done cautiously.

The principal contribution of this paper is to put this between-area migration data on a consistent geographical basis, so that like is compared with like over the full time series. This is done just for England and Wales, as Scotland and Northern Ireland have different recording systems maintained by their separate national agencies (see Lomax et al, 2013). It draws primarily on a suite of origin/destination matrices, one for each year ending in June for 1976-2011 and each on the basis of the contemporary health areas, thus revealing how the NHSCR geography altered over the 36 years. As it was found that most of the changes involved the splitting or merger of areas, the approach was to identify the lowest common denominator (LCD), resulting in a total of 80 areas (see Appendix).

\section{THE RESULTS}

This section sets out the findings derived from collapsing the full migration matrix of between-area flows for each year to the consistent geography of 80 areas. Before examining the picture for all flows, a separate look is taken at the trend for betweenregion flows and then at the flows between areas within regions, parallel to the US distinction between 'inter-state' and 'inter-county within-state' flows. When we come to combine these two types of flow, we can also compare them directly to see whether there are any major differences in their trajectories. Additionally, at each stage, the all-persons rates are disaggregated by broad age groups, as this enables the isolation of the main student age group - a useful precaution given the concerns described above.

\section{Migration between the Regions of England and Wales}

The results of calculating rates of between-region migration are shown in Figure 1. Two series are shown that relate to two different sets of English regions, allowing coverage back to 1971 and in the process demonstrating the importance of keeping to a consistent geography. The series that begins with the year ending June 1972 is based on the Standard Statistical Regions that were used for the reporting of English regional statistics until the mid-1990s. The general pattern is the one that is familiar from the previous studies reviewed above, most notably Stillwell et al (1992b) who observed a substantial decline in migration rate from a high around 1970, followed by an even steeper rise after 1981 as the country moved out of recession. It then shows that the rate peaked in 1988 before plunging even more steeply into the 1990/91 recession. Clearly, the patterning of this 23-year SSR-based series is dominated by the effects of economic cycles and, by itself, does not provide a firm basis for detecting any longer-term trend in the intensity of between-region migration.

Figure 1 about here

The other series shown in Figure 1 uses Government Office Regions (GORs) for England and extends the record for a further 17 years to 2011, when there was another major discontinuity, this time due to methodological changes. This shows that, after the blip of 1992, there was a steady increase in rate till 1997, followed by a plateauing 
for the next 7 years. In 2005 it dropped by a point and then between 2007 and 2009 it dropped by another 1.5 points. The main conclusion from this series is that the trend since the early 1990s has been much less volatile than before then, but this could have its roots in the economy, given the 'long boom' that occurred after the 1990-91 recession and was little affected by the 'dot-com recession' of 2001). It is notable that the first dip in the migration rate predates the 2008-09 recession by three years, but rather than being seen as an early-warning signal this dip may be linked to the surge in labour migration from the 8 East European countries that joined the European Union in 2004, this possibly reducing the need for and/or opportunity of inter-regional migration by the native population in search of work.

The fact that the GOR-based rate is substantially higher than the SSR-based rate over their common period of 1975-1994 is testament to the major effect that a changing geography of reporting units, can have on between-area flows. The key change between the two geographies relates to south-eastern England, which the SSR system split into two regions - East Anglia with just three counties and the 13 counties of the South East SSR including Greater London - but now comprises three regions, of which the county of Greater London is one. As the latter substantially underbounds the London urban area and even more so its labour and housing market areas, it is strongly linked to its surrounding counties by migration flows in both directions. Indeed, more detailed analysis (not shown here) reveals that in most years from 1975 onwards at least one-fifth of the between-region migration shown for the GOR-based system in Figure 1 is made up of just the flows between London and its two adjacent regions.

Figure 2 disaggregates the overall rate into the five broad age groups that ONS provides from 1975/76. The most impressive feature is the way in which the rate for 16-24 year olds shoots up from just over 40 per thousand in 1991 to 65 in 1996 and stays at around this level for another 5 years before steadily falling back and stabilising at around 53-54 per thousand for the last 5 years of the study period. While it is expected that the rate for 16-24s is much higher than for the other age groups, the scale of the post-1991 increase is completely out of line with the trend for the other four age groups, for which there is much less volatility and the only detectable trends are that since 1990 the rates for the under-16s and the $65+s$ are somewhat lower than previously. The primary explanation for the rise in the 16-24s rate must lie in the expansion of higher education then, linked to the strong tradition of attending a nonlocal university. The fact that the rate subsided in the final decade is likely to be associated with the introduction of tuition fees, not markedly affecting participation but encouraging more to attend universities in their home area.

Figure 2 about here

A more precise test of longer-term tendencies can be undertaken by averaging out rates over periods that span economic cycles. A starting point is to divide the full period 1971-2011 shown in Figure 1 into four separate decades, using the GOR-based overall rate for 1975-2011 along with the ratio method for estimating the 1971-75 rates on this basis. The result yields an average annual rate of 21.0 per 1000 for 197181, which compares with 19.9 for 1981-91, 20.9 for 1991-2001 and 20.4 for 20012011. The overall impression from this calculation is of relatively little long-term change in the intensity of between-region migration, with the latest decade's rate 
being only some 3 per cent below that of the 1970s. It has, however, to be born in mind that the overall rate for the 1990s is boosted by the sharp rise in the 16-24s' rate, which might be considered a special feature in the wider scheme of things (see above). To allow for that, one needs to focus on the age-specific series available from 1975. Also, given the 'long boom' before the recession of 2008-09, a minimum of 15 years is really needed to neutralise the cyclical effect.

Figure 3 takes both these latter points on board by showing the 15-year running averages for each of the five age groups, as well as for all ages and also for all ages bar the 16-24s, with the series running from the 15 years ending 1990 (i.e. July 1975 to June 1990) to those ending 2011 (i.e. July 1996 to June 2011). On this basis, the all-ages running average starts at 20.0 per 1000 and ends up a little higher at 20.8 (an index of 103.7 if the initial observation is set at 100), but this increase is primarily due to the boost given by the 16-24s whose average rate rises from 45.2 to 58.9 (an index of 139.1). Excluding the 16-24s, the running average rate drops somewhat from 16.4 to 15.9 per 1000 (an index of 96.9, i.e. a decline of around 3 per cent). Taking the other four age groups separately, the index of the endpoint of the series is 90.7 for the $0-15$ s, 103.1 for the 25-44s, 100.9 for the 45-64s and 74.4 for those aged 65 and over. In case the 15-year averages are seen as inadequate for allowing for the business-cycle effect, the indices for the 20-year running averages for these four age groups are, respectively, 93.4, 102.7, 101.2 and 79.8.

Figure 3 about here

The conclusion from this set of calculations, therefore, is that since the 1970s there has been a marked reduction in the propensity of those aged 65 and over to make a between-region move and a somewhat smaller reduction for the under-16s. By contrast, the other three age groups have not shared this tendency. The small increase in rate for the 25-44s and 45-64s does not wholly offset the declines at the age extremes, but the steep rise in rate for the 16-24s that is consistent with increasing participation in higher education shifts the overall rate from the 2-3 per cent overall decrease for the other four age groups combined to a 3-4 per cent increase.

\section{Migration within the Regions of England and Wales}

How does the long-term trend for within-region migration differ from what we have just seen for between-regional migration? Does it follow a similar pattern in the same way as the largely parallel trend of between-state and between-county within-state migration in the USA? This section answers these questions by reference to the subregional migration dataset that, as described above, has been put on a geographical basis that is consistent over the full time period from 1975/76 onwards. The data refers to migration between areas but not crossing a regional boundary.

Figure 4 shows the trend in within-region migration rate for all ages combined and compares this with the unadjusted series so as to demonstrate the importance of allowing for the changing geography of health areas. The two series are quite similar over the first decade of the study period when there was the need to collapse Wales into just two areas for the consistent series, but widens in the late 1980s when an increasing proportion of the Middlesex records were being allocated to the five areas into which this former county was split. The gap narrows markedly in 1999 when 
health-service reorganisation temporarily involved much amalgamation before there was considerable splitting of areas that lasted until 2008. The adjustment for 20012008 is especially crucial because the unadjusted series gives the impression of accelerated within-region migration in the 2000s, while also suggesting a sharp decline around the time of the 2008-09 recession. The reality is that the rate peaked in 1998 and then subsided somewhat, with the impact of recession being relatively muted. The decadal average rate for 2001-11 was the highest of the period at 13.8 per 1000 compared with 13.7 for 1991-2001, 12.5 for 1981-91 and 13.0 for the six years 1975-81. Clearly no long-term reduction is evident since the 1980s.

Figure 4 about here

Is this rise in within-region migration rate since the 1980s found for all age groups, or is there a 'student effect' operating here like for between-region migration? Figure 5 reveals an acceleration in rate for the 16-24s between 1992 and 1996 that in relative terms is not much smaller than that in Figure 2. Just as for inter-region migration, the 16-24 rate then drops away in the 2000s, in this case ending up in 2011 at around the same level as at the start of the study period in the mid-1970s. But there is also evidence of buoyancy in the rates for the 25-44s and 45-64s, which both end up higher than at the start, and it is only for the $65+$ group that the rate would appear to be running at a lower level in more recent years.

Figure 5 about here

Figure 6 attempts to allow for the effect of economic cycles by showing 15-year running averages in the same way as for between-region migration in Figure 2. It confirms the generally upward trajectory of the 16-24s, for whom the average rate at the outset (July 1975 to June 1990) was 22.5 per 1000 and at the end (July 1996 to June 2011) was 27.1, an increase of 20.4 per cent. But even excluding the 16-24s the average rate was higher at the end than at the start, with equivalent figures of 11.2 and 12.3 per 1000 and a relative rise of 9.4 per cent. The only age group where the longterm trend declined was for those aged 65 and over, down by 10.5 per cent from an average of 5.5 to 4.9 per 1000 between 1975-90 and 1996-2011. The other three ages registered long-term gains, though not as large as for the 16-24s: for 25-44s, up by 15.7 per cent from 18.2 to 21.1 per 1000 ; for $45-64$ s, up by 11.7 per cent from 6.3 to 7.1 per 1000; and for 0-15s, up by 3.0 per cent from 11.5 to 11.8 per 1000 .

Figure 6 about here

\section{All Inter-Area Moving}

This third and final section of empirical results examines the two series combined as well as comparing them. Figure 7 shows the full between-region time series from June 1971 (the GOR-based version with estimates for 1971-75), as well as the withinregion and combined series from the start of the sub-regional data in 1975 . The within-region rate is consistently lower than the between-region one, which is due primarily to the former excluding within-area moves but is also affected by having to reduce the number of sub-regional units in order to achieve a consistent geography over time and by the between-region series including flows between an underbounded London and its adjacent regions. As regards their patterns over time, there 
appears to be a relatively close fit between the two, both experiencing the three recessionary lows, though with the between-region rate being the somewhat more sensitive to economic cycles.

Figure 7 about here

As regards the key question of the long-term trend, Figure 7 does not indicate any strong decline in migration intensity along the lines of that observed for the USA. Instead, the rates for the second half of the study period generally fall within the range of observations found for up to the early 1990s. Certainly the between-region rate in the latest recession was no lower than it had been at the time of the two previous ones. While the extension of this series back to the early 1970s might seem to suggest a longer-term decline from the 1960s, the evidence provided by the Census for then (see above) disproves this, as the 1960s was a decade of accelerating migration that presumably peaked around 1970 . The within-region rate seems to have been generally higher in the second half of the period, but it would probably have been below that of the early 1970s if data had been available for then.

Finally, there is the question of how much this resilience of overall migration rates is the result of the post-1990 increase in higher-education participation. Figure 8 shows the result when the 16-24s are omitted from the rates calculation, this chart running from 1975-76 as this was the first year for which age was recorded in the NHSCR (see above). The omission of the 16-24s does lower the rate for the post-1992 period compared to the trajectory in Figure 7, but the overall conclusion is broadly the same. While the last three years of the between-region rate are now amongst the lowest recorded, the combined rate of between-area moves for the second half of the study period is consistently within the range found for the first half.

Figure 8 about here

\section{CONCLUDING COMMENTS}

The aim of the analyses reported above has been to see whether any significant decline in between-area migration rates has occurred in England and Wales in recent decades along the lines of that observed in the USA. This has proved a challenging task, not least because of the short-term volatility associated with business cycles, the related inadequacy of the one-year-in-ten data from the Population Census and the changing geographies of the NHSCR dataset used here. Nevertheless, the main conclusion is clear. In England and Wales there has been no substantial long-term decline in the overall intensity of between-area migration since the 1970s, unlike for inter-county moves in the USA. This is the case for both the rate of between-region migration and also the rate of migration between areas within these regions. While there has been a drop in the long-term rate for those aged 65 and over, the rates for the other four age groups have been essentially stable or increased.

This was not the result that we expected at the outset of the study. As mentioned above, while there are certain differences between the USA and England and Wales such as in welfare provision, immigration history and geographical scale, there are also many features that are shared by the Anglo-American world. Both have 
experienced structural labour market occupational and sectoral shifts, changing social and geographical patterns of economic activity, population aging, and advances in transport and communication technologies. In other words, both could be described as representatives of the same basic type of advanced consumerist free market society, albeit with national variations but whose similarities outweigh their differences. Given this world view, it might be expected that England and Wales would have the same migration experience as the USA, with both falling into the class of 'super-advanced societies' in the final stage of Zelinsky's model (1971) where some migration has been substituted by other types of mobility and with England and Wales experiencing the rise of 'secular rootedness' noted by Cooke (2011) for the USA. These types of structural arguments are attractive because they deal with large social, economic and demographic forces, attempt to relate them to migration, and also unify several disciplinary fields of study.

Our negative result prompted us to triangulate with a very different source, which as reported in the companion paper to this one (Champion and Shuttleworth, 2016) broadly confirms the stability of longer-distance migration rates in England and Wales since the 1970s. This suggests that there are serious limitations to this type of generalising conceptual approach, such that if we want to set internal migration in its wider context, we need to think far more flexibly about social change, migration, and the ways in which general structural social forces are felt by individuals and mediated in different national contexts. The difference in the experience across the Atlantic suggests that advanced economies are not all the same in their migration response to economic circumstances (e.g. the recent recession and de-industrialisation since the 1970s), technical change (e.g. the growth of internet technologies), and demographic change (e.g. population aging), and therefore that it is not possible to generalise from the experience of the USA (Coulter et al, 2015) in all regards. National diversity within the class of 'advanced economies' might outweigh similarities within this group; forces that have pushed down longer-distance migration in the USA might not operate in the same way in the UK or else be counteracted by other factors which serve to drive migration rates up; and, more generally, generalising theories may just be too general - it might be that national diversity is really the key factor to consider. In these circumstances, the factors identified earlier in the paper as explaining the fall in US long-distance migration may be necessary but not sufficient when applied to other national contexts, and the task for migration researchers will be to assess how far general social forces that have profoundly reshaped societies across the world have diverse and different national outcomes according to specific national contexts. These observations and comments underline the need for a wider comparative international research agenda.

\section{ACKNOWLEDGEMENTS}

The authors thank the Office for National Statistics (ONS) for providing the NHSCR migration matrices for the 36 years ending June, 1976-2011. The data are Crown Copyright. The authors are entirely responsible for the calculations derived from the data and the interpretation of the results. 


\section{REFERENCES}

Adey P. 2010. Mobility. Routledge: Abingdon, Oxon.

Barr R, Shuttleworth I. 2012. The accuracy of internal migration estimates using address information from health card registrations with General Practitioners: Perspectives from Northern Ireland using the Northern Ireland Longitudinal Study (NILS). Health and Place 18: 595-604.

Bauman Z. 2000. Liquid Modernity. Polity Press: Cambridge.

Bell M, Charles-Edwards E. 2013. Cross-national Comparisons of Internal Migration: An Update on Global Patterns and Trends. Technical Paper No. 2013/1. United Nations Department of Economic and Social Affairs: New York.

Bell M, Charles-Edwards E, Kupiszewska D, Kupiszewski M, Stillwell J, Zhu Y. 2015a. Internal migration data around the world: assessing contemporary practice. Population, Space and Place 21: 1-17.

Bell M, Charles-Edwards E, Ueffing P, Stillwell J, Kupiszewski M, Kupiszewska D. 2015b. Internal migration and development: comparing migration intensities around the world. Population and Development Review 41: 33-58.

Castles S, Millar MJ. 2009. The Age of Migration. Palgrave Macmillan: Basingstoke, $4^{\text {th }}$ edition.

Champion T. 2005. Population movement within the UK. In Focus on People and Migration, Chappell R (ed). Palgrave Macmillan: Basingstoke; 91-113.

Champion T, Fielding T (eds). 1992. Migration Processes and Patterns Volume 1: Research Progress and Prospects. Belhaven Press: London.

Champion T, Shuttleworth I. 2016. Are people moving home less? An analysis of migration within England and Wales, 1971-2011, by distance of move.

Population Space and Place DOI: awaited.

Cooke TJ. 2011. It is not just the economy: declining migration and the rise of secular rootedness. Population, Space and Place 17: 193-203.

Cooke TJ. 2013. Internal migration in decline. The Professional Geographer 65: 664675.

Coulter R, van Ham M, Findlay A. 2015. Re-thinking residential mobility: Linking lives through time and space. Progress in Human Geography OnlineFirst DOI: 10.1177/0309132515575417.

Cresswell T. 2006. On the Move: Mobility in the Modern Western World. Taylor and Francis: London.

Devis T. 1984. Population movements measured by the NHSCR. Population Trends 36: $18-24$.

Fielding T. 2012. Migration in Britain. Edward Elgar: Cheltenham.

Frey WH. 2009. The Great American Slowdown: Regional and Metropolitan Dimensions. Metropolitan Policy Program, Brookings Institution: Washington DC.

Green A. 1992. Changing labour market processes and internal migration. In Migration Processes and Patterns Volume 1: Research Progress and Prospects, Champion T, Fielding T (eds). Belhaven Press: London; 105-118.

Green A, Shuttleworth I. 2015. Labour markets and internal migration. In Internal Migration: Geographical Perspectives and Processes, Smith D, Finney N, Halfacree K, Walford N (eds). Ashgate: Farnham, Surrey; 65-79.

Hannam K, Sheller M, Urry J. 2006. Editorial: Mobilities, immobilities and moorings. Mobilities 1: 1-22.

Jaffe E. 2012. The mystery of declining mobility. The Atlantic Cities, December 17. 
Kaplan G, Schulhofer-Wuhl S. 2012a. Interstate migration has fallen less than you think: Consequences of hot desk imputation in the Current Population Survey. Demography 49: 1061-1074.

Kaplan G, Schulhofer-Wuhl S. 2012b. Understanding the Long-Run Decline in Interstate Migration. National Bureau of Economic Research Working Paper 18507. NBER: Cambridge MA.

Kaplan G, Schulhofer-Wuhl S. 2012c. Understanding the Long-Run Decline in Interstate Migration. Working Paper 697. Federal Reserve Bank of Minneapolis: Minneapolis.

Lee ES. 1966. A theory of migration. Demography 3: 47-57.

Lomax N, Norman P, Rees P, Stillwell J. 2013. Subnational migration in the United Kingdom: producing a consistent time series ising a combination of available data and estimates. Journal of Population Research 30: 265-288.

Lomax N, Stillwell J, Norman P, Rees P. 2014. Internal migration in the United Kingdom: analysis of an estimated inter-district time series, 2001-2011. Applied Spatial Analysis and Policy 7: 25-45.

Lowery A. 2013. Why are Americans staying put? New York Times, December 10.

Molloy R, Smith CL, Wozniak A. 2011. Internal migration in the United States. Journal of Economic Perspectives 25: 173-196.

Molloy R, Smith CL, Wozniak A. 2013. Declining Migration within the US: The Role of the Labor Market. Federal Reserve Board of Governors: Washington DC.

ODPM. 2002. Development of a Migration Model. Office of the Deputy Prime Minister: London.

Ogilvie AA. 1982. Population migration between the regions of Great Britain, 1971-9. Regional Studies 16: 65-73.

Partridge MD, Rickman DS, Olfert MR, Ali K. 2012. Dwindling US internal migration: Evidence of spatial equilibrium or structural shifts in local labor markets? Regional Science and Urban Economics 42: 375-388.

Robins K. 2000. Encountering globalization. In The Global Transformation Reader, Held D, McGrew AG (eds). Polity Press: Cambridge.

Rosenbaum M, Bailey J. 1991. Movement within England and Wales during the 1980s, as measured by the NHS Central Register. Population Trends 65: 24-34.

Sheller M, Urry J. 2006. The new mobilities paradigm. Environment and Planning A 38: 80-93.

Smith D, Finney N, Halfacree K, Walford N (eds). 2015. Internal Migration: Geographical Perspectives and Processes, Ashgate: Farnham, Surrey.

Stillwell J, Rees P, Boden P (eds). 1992a. Migration Processes and Patterns Volume 2: Population Distribution in the United Kingdom. Belhaven Press: London.

Stillwell J, Rees P, Boden P. 1992b. Internal migration trends: an overview. In Migration Processes and Patterns Volume 2: Population Distribution in the United Kingdom, Stillwell J, Rees P, Boden P (eds). Belhaven Press, London; 2855.

Urry J. 2007. Mobilities. Polity: Oxford.

Wolf DA, Longino CF. 2005. Our ‘increasingly mobile society’? The curious persistence of a false belief. The Gerontologist 45: 5-11.

Zelinsky W. 1971. The hypothesis of the mobility transition. Geographical Review 61: 219-249. 
Appendix. The 80 areas comprising a consistent NHSCR-based geography for years ending June, 1976-2011, by former Government Office Region

\begin{tabular}{|c|c|c|}
\hline North East (6) & East Midlands (5) & London (12) \\
\hline Gateshead \& South Tyneside & Derbyshire & Middlesex \\
\hline Newcastle \& North Tyneside & Leicestershire & Barking \& Havering \\
\hline Sunderland & Lincolnshire & Bexley \& Greenwich \\
\hline Cleveland/Tees & Northamptonshire & Bromley \\
\hline Durham & Nottinghamshire & Camden \& Islington \\
\hline \multirow[t]{2}{*}{ Northumberland } & & City \& Newham \& Tower Hamlets \\
\hline & West Midlands (11) & Croydon \\
\hline North West (12) & Birmingham & Kensington \& Chelsea \& Westminster \\
\hline Liverpool & Coventry & Kingston \& Richmond \\
\hline Sefton & Dudley & Lambeth \& Southwark \& Lewisham \\
\hline St Helens \& Knowsley & Sandwell & Merton \& Sutton \& Wandsworth \\
\hline Wirral & Solihull & Redbridge \& Waltham Forest \\
\hline Bury \& Rochdale & Walsall & \\
\hline Wigan \& Bolton & Wolverhampton & South East (9) \\
\hline West Pennine & Hereford \& Worcester & Berkshire \\
\hline Manchester & Shropshire & Buckinghamshire \\
\hline Salford & Staffordshire & East Sussex \\
\hline Stockport & Warwickshire & Hampshire \\
\hline Cheshire & & Isle of Wight \\
\hline \multirow[t]{2}{*}{ Cumbria \& Lancashire } & Wales (2) & Kent \\
\hline & North Wales \& Dyfed \& Powys & Oxfordshire \\
\hline Yorkshire \& The Humber (10) & Morgan \& Bro Taf \& Gwent & Surrey \\
\hline Barnsley & & West Sussex \\
\hline Doncaster & East of England (6) & \\
\hline Rotherham & Bedfordshire & South West (7) \\
\hline Sheffield & Cambridgeshire & Avon \\
\hline Bradford & Essex & Cornwall \\
\hline Calder \& Kirklees & Hertfordshire & Devon \\
\hline Leeds & Norfolk & Dorset \\
\hline Wakefield & Suffolk & Gloucestershire \\
\hline Humber & & Somerset \\
\hline North Yorkshire & & Wiltshire \\
\hline
\end{tabular}

Source: Own work (see text). 


\section{FIGURES}

Figure 1. Between-region migration rate, for years ending June, 1972-2011, using alternative regional geographies (Source: calculated from the NHSCR-based migration matrix supplied by ONS. Crown Copyright.)

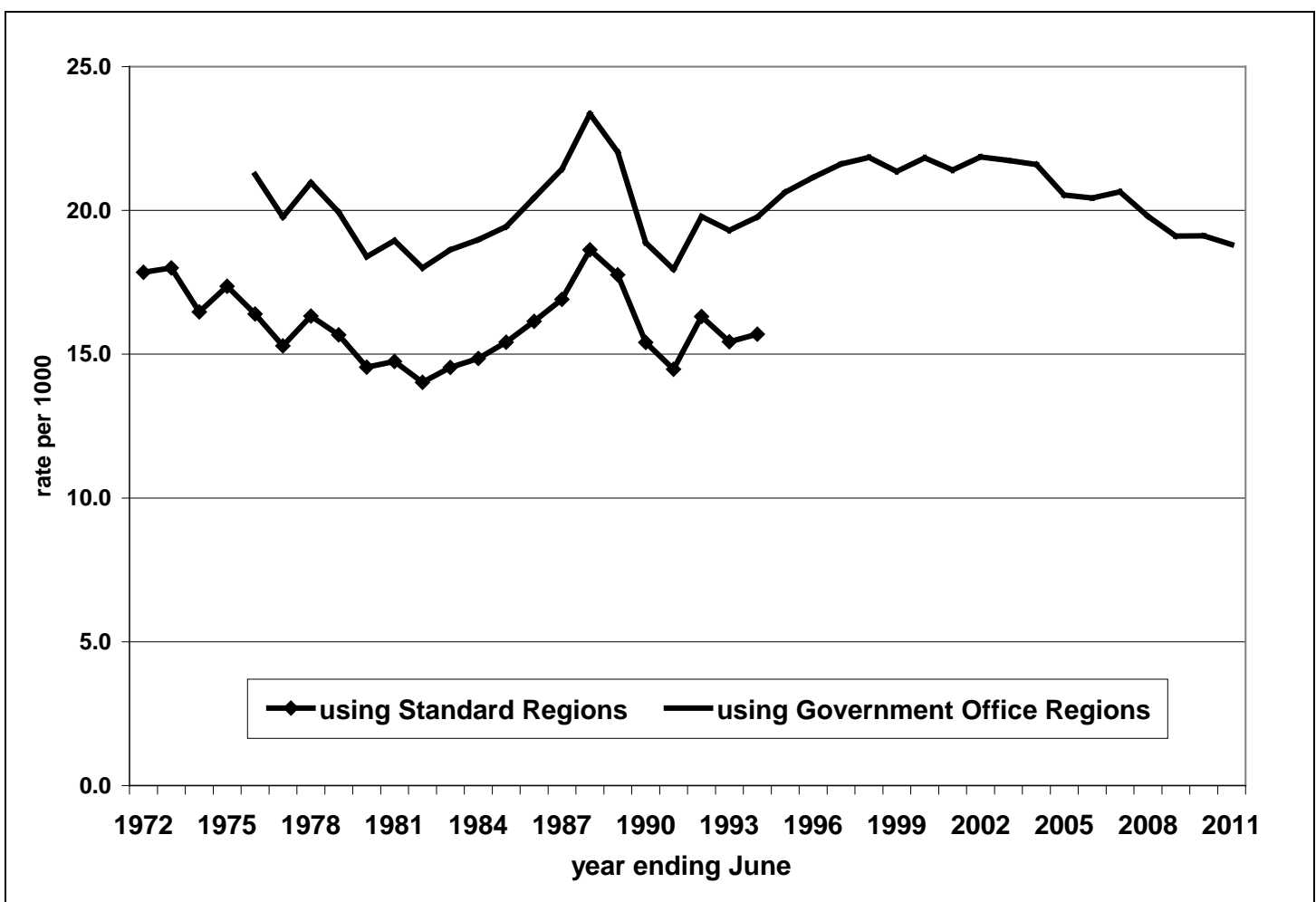


Figure 2. Migration rate between the former Government Office Regions of England and Wales for years ending June, 1976-2011, by age (Source: see Figure 1)

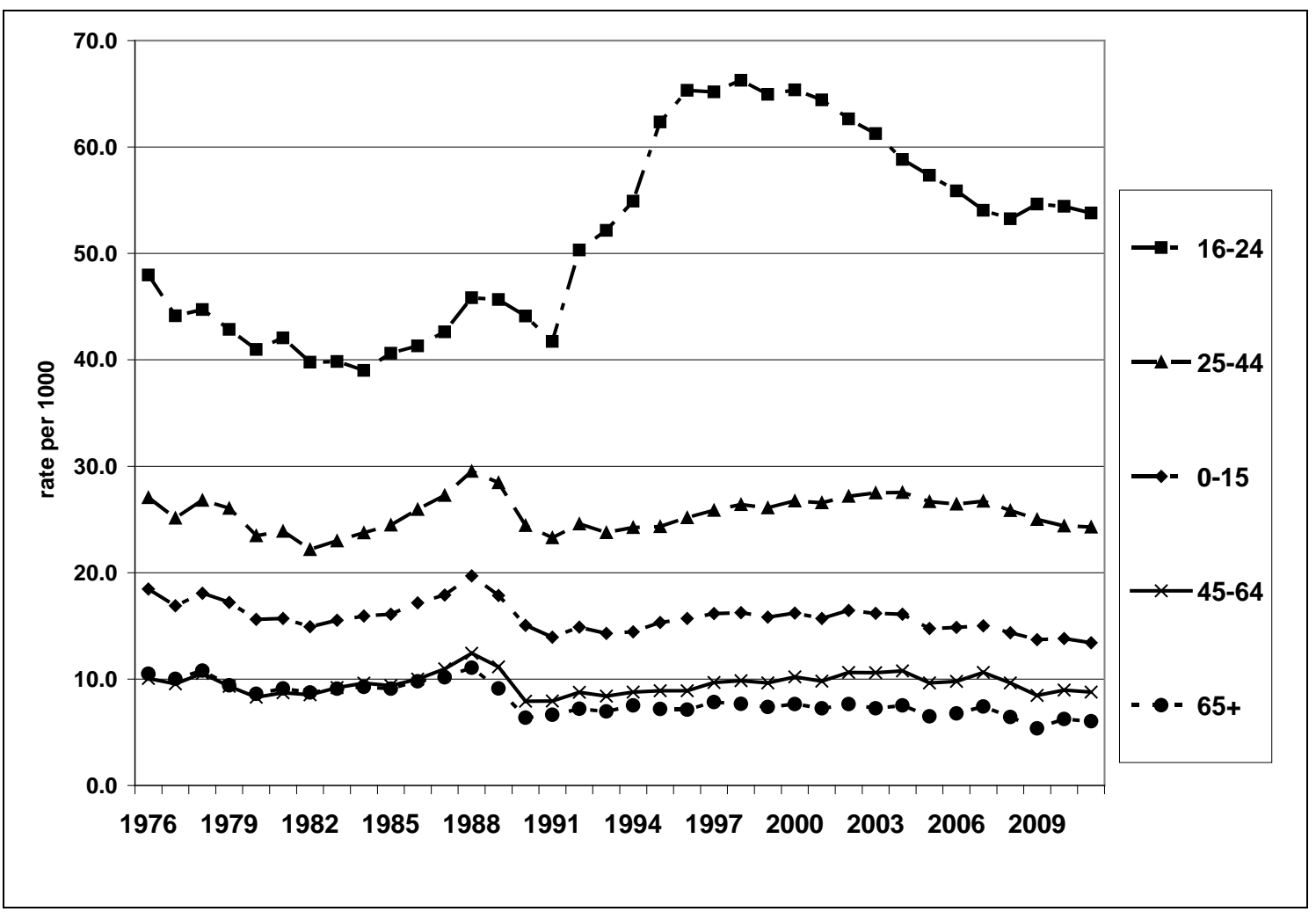

Figure 3. 15-year running averages of migration between the former Government Office Regions of England and Wales, by age (Source: see Figure 2)

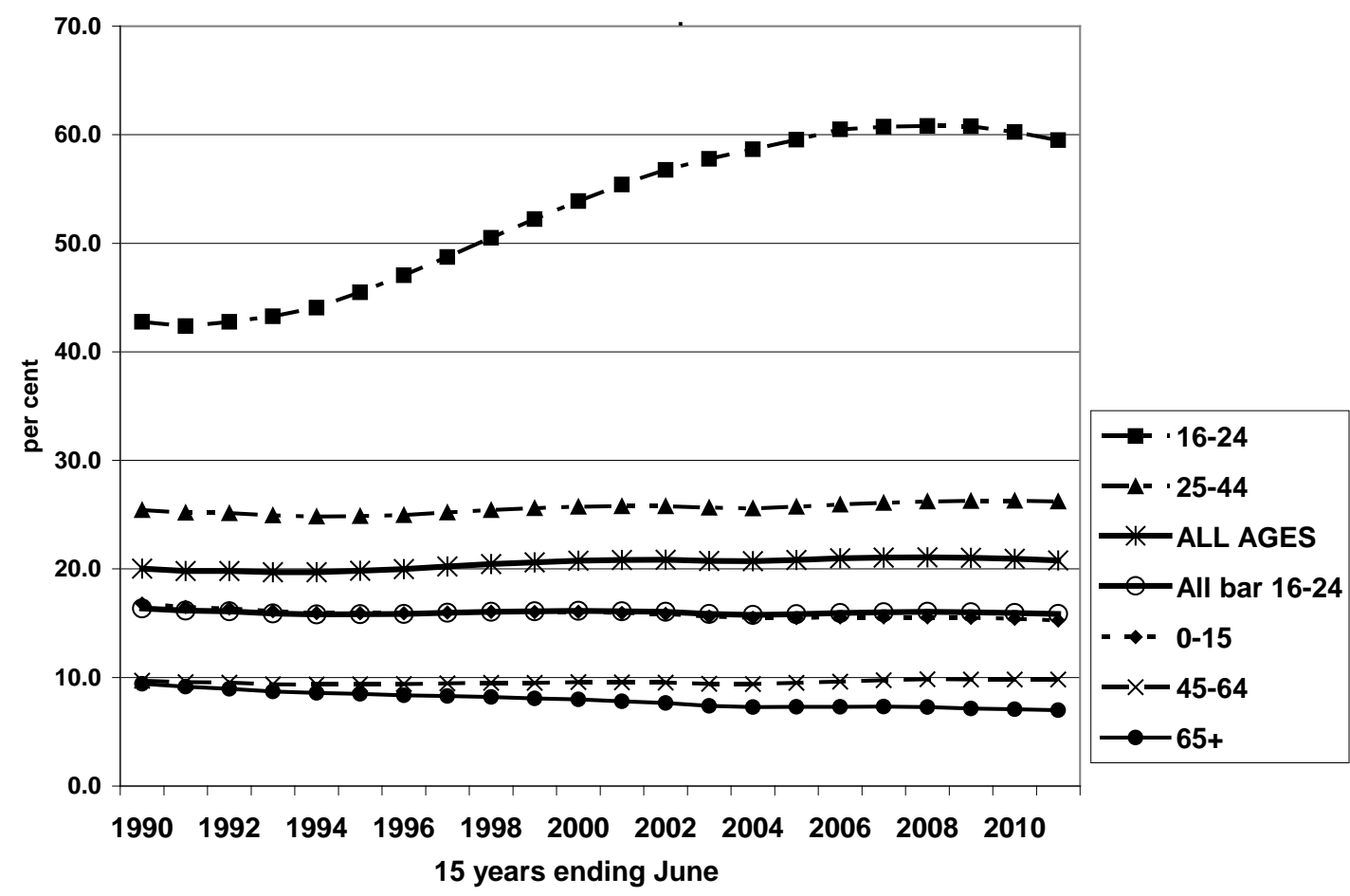


Figure 4. Within-region migration rate, for years ending June, 1976-2011, all ages, for a consistent geography compared with those recorded using contemporary NHSCR areas (Source: See Figure 2)

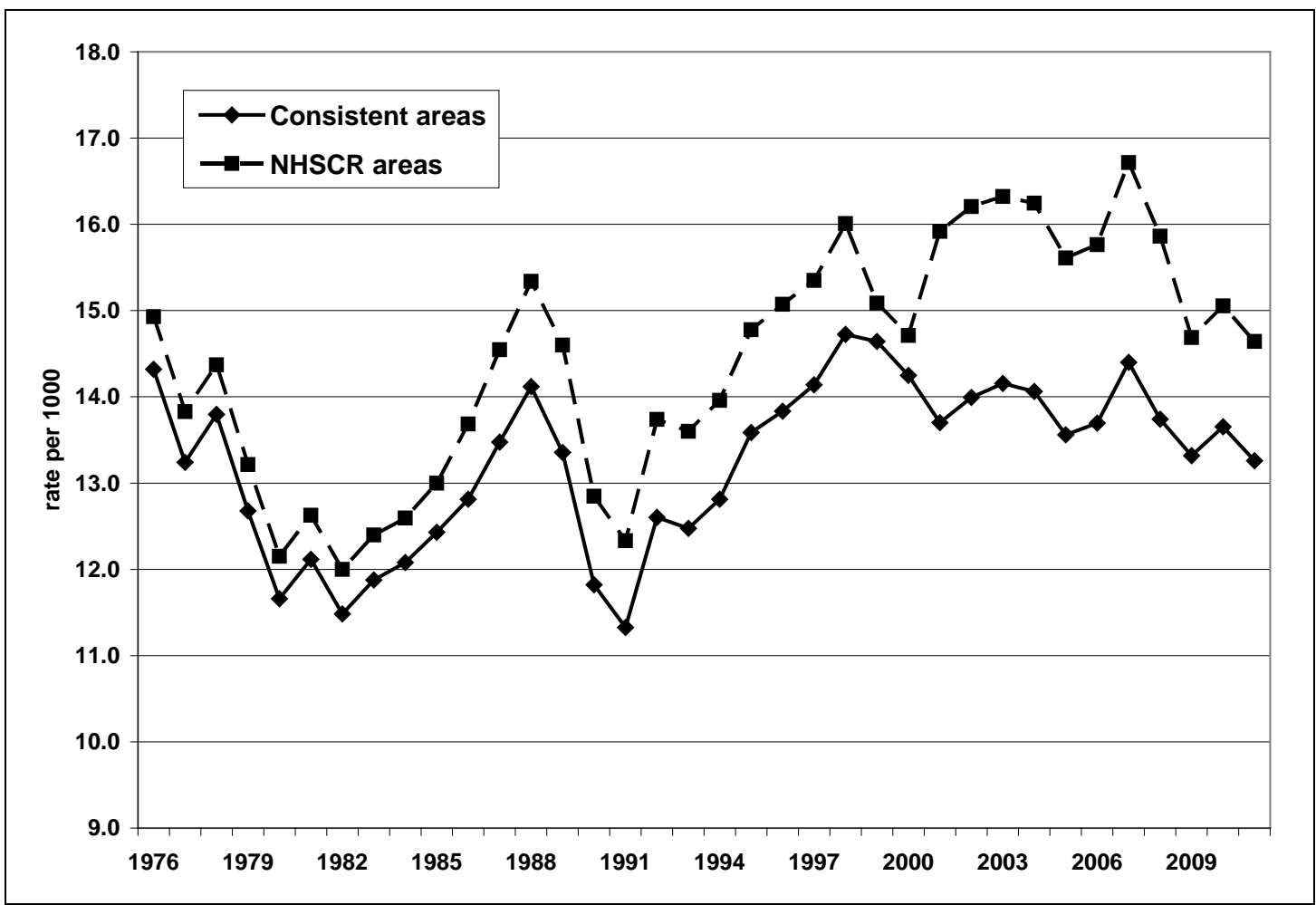

Figure 5. Rate of migration between areas within regions for years ending June, 19762011, by age (Source: see Figure 2)

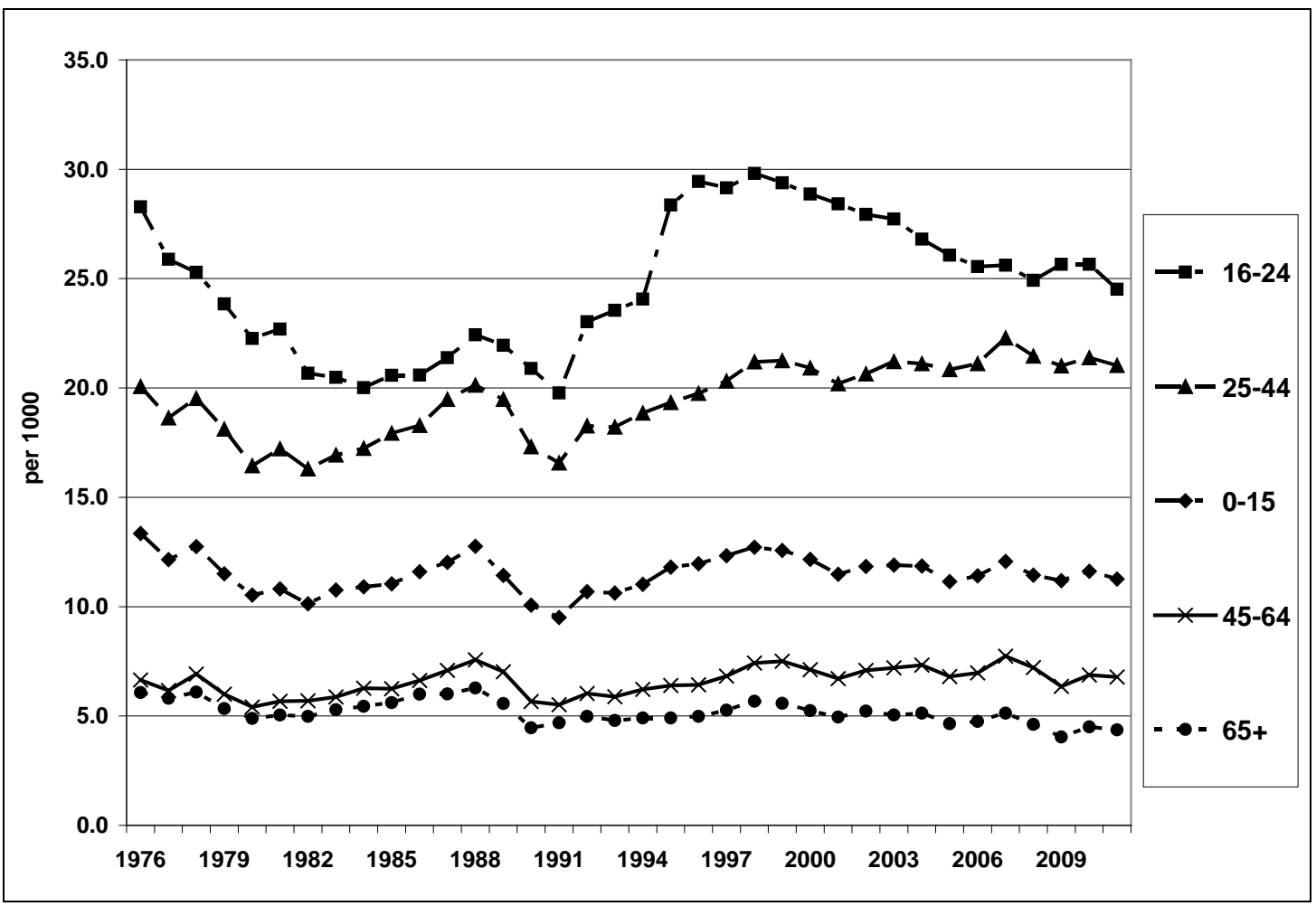


Figure 6. 15-year running averages of migration between areas within regions, by age (Source: see Figure 2)

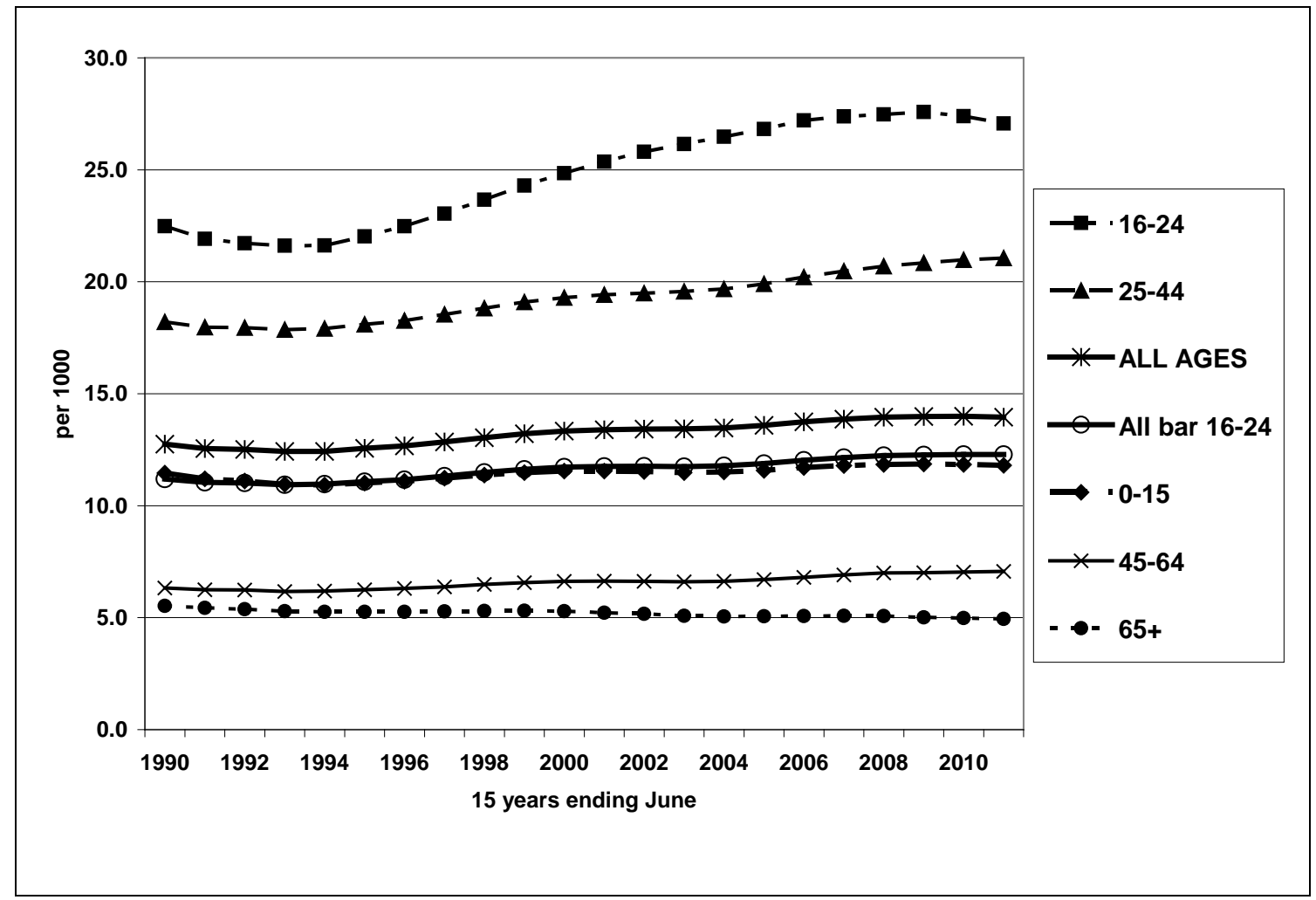

Figure 7. Migration rate, 1971-2011, all ages, for between-region, within-region and all inter-area moves

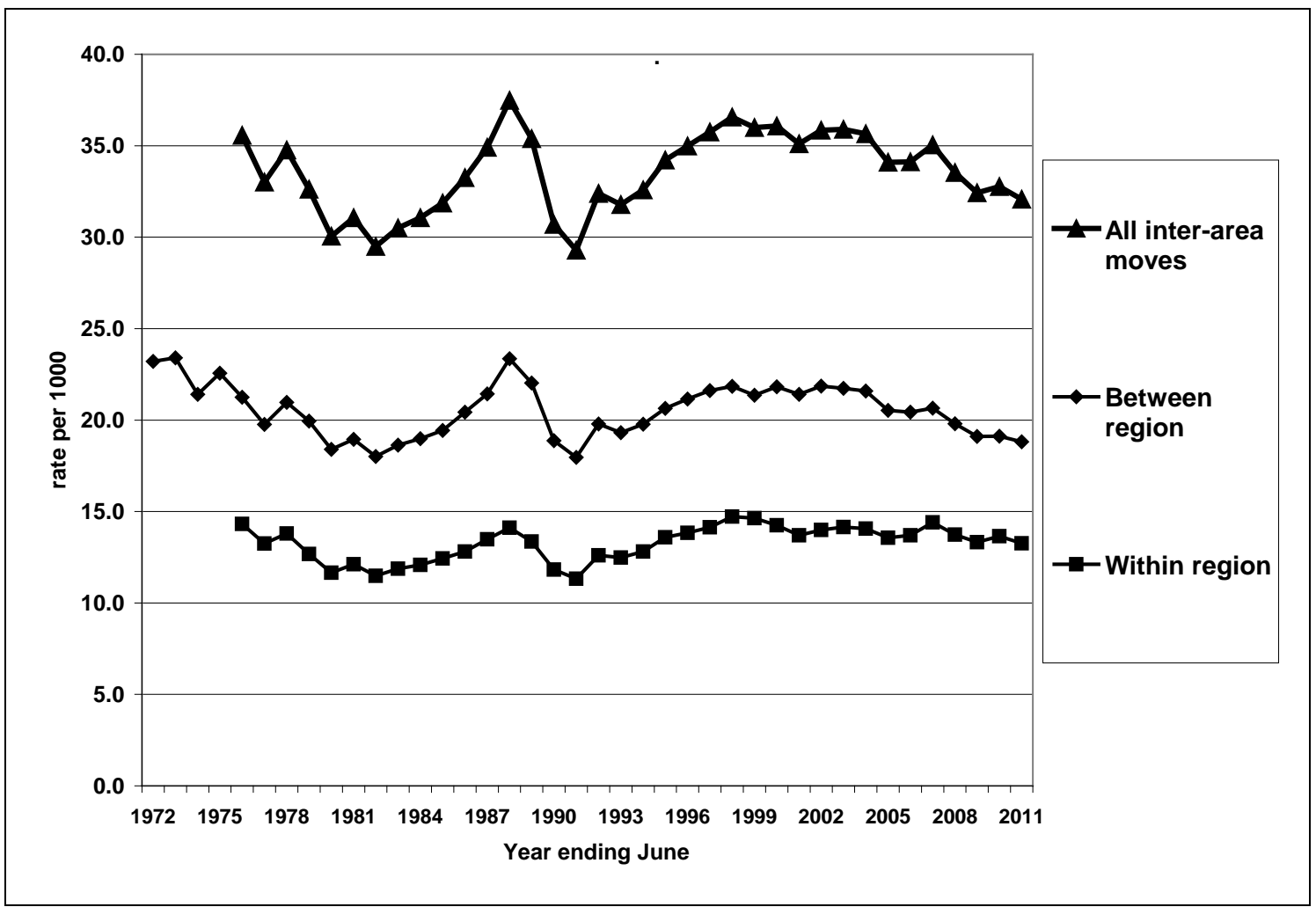


Figure 8. Migration rate, 1975-2011, all ages bar 16-24, for between region, withinregion and all inter-area moves

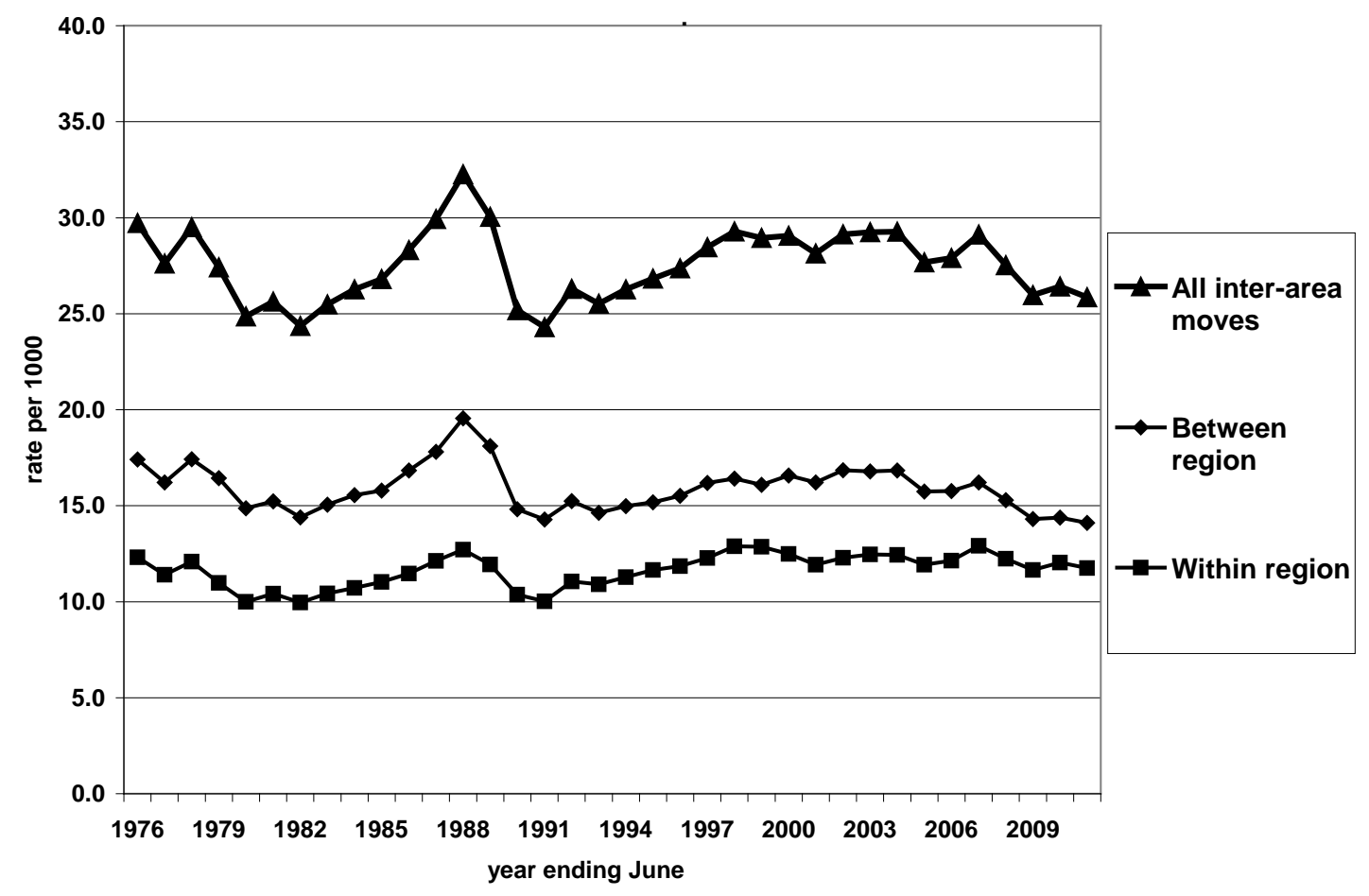

